\title{
Clinical trials in India: At uncertain crossroads?
}

The Gazette Notification issued on January 30, 2013 by Central Drugs Standard Control Organization (CDSCO), Ministry of Health and Family Welfare, Government of India has had far reaching impact on the planning, initiation, conduct and culmination of clinical trials in India. ${ }^{[1]}$ The Notification itself was a hurried response to a petition in the Supreme Court by health activists that alleged widespread violations of ethical conduct by sponsors and investigators, specifically in the context of human papilloma virus vaccine trials in vulnerable populations. A review of the clinical trial process in India, including its oversight, was long overdue, and this judicial petition presented a welcome opportunity to all stakeholders to give it the right direction. However, even a cursory perusal of the Notification reveals the slack manner in which it has been drafted - almost guaranteed to throw out the baby with the bathwater.

Several glaring errors of omission and commission in this Notification have already been pointed out by several individuals and associations. The most notable include requirement for providing compensation to trial subjects in the event of failure of intended therapeutic effect of an experimental drug and unrealistic definitions of timelines for reporting adverse events. ${ }^{[2,3]}$ Others have perceptively pointed out that the most devastating impact of these regulations would be on investigator initiated research, which, ironically, has the greatest potential of providing cost-effective solutions to India's health problems. ${ }^{[4]} \mathrm{A}$ number of developments subsequent to Notification merit careful consideration, most notably Professor Ranjit Roy Chaudhury Committee Report and its recent partial implementation including a further order mandating the audiovisual recording of informed consent process for all clinical trials conducted in India. ${ }^{[5-7]}$

However, before we do so, it is pertinent to point out that the clinical trials scenario in India has long been very unsatisfactory from an ethical point of view. ${ }^{[8-11]}$ Major concerns have included poor quality (sometimes even lack) of informed consent, poor quality of scientific and

\begin{tabular}{|l|l|}
\hline \multicolumn{2}{|c|}{ Access this article online } \\
\hline Quick Response Code: & Website: \\
& www.ijmpo.org \\
& \\
& \\
\hline
\end{tabular}

ethical review especially that involving independent ethics committees, suboptimal regulatory approval process for new drugs and clinical trials, inadequate protection of the rights of patients including compensation for research related injury and the question of post-trial population access to prohibitively expensive drugs that are tested in clinical trials in this country. Many responsible stakeholders have been urging a comprehensive overhaul of this system for a long time including augmentation of the capacity of state and federal regulatory mechanisms so that they can satisfactorily fulfill their obligations.

Unfortunately, the remedy turned out to be worse than the disease. The CDSCO Notification, in one fell swoop, swung the pendulum from one extreme of laxity to the other of draconian, unjustified, throttling regulation. It is unsettling to note that this process of amending the existing rules has been utterly nonparticipatory, with no stakeholder (investigators, patients, advocacy and patient support groups, pharmaceutical companies, research organizations, ethicists, others) being involved in a structured manner. If someone wishes to point out the perfunctory request for public comments that accompanies each so called "draft", it is a common experience that responses are almost never considered or even acknowledged. It is worth pointing out that this is quite contrary to the democratic ethos that our society swears by. In a belated realization of the negative impact of its Notification, the Health Ministry set up a Committee chaired by Professor Ranjit Roy Chaudhury to suggest course correction - a classic example of acting in haste and repenting at leisure. The Committee expeditiously submitted its report and, on the whole, did a commendable job of striking some balance between various competing concerns. ${ }^{[5]}$ Among its welcome recommendations were those involving accreditation of investigators and centers engaged in clinical trials, strengthening the infrastructure and capacity of CDSCO to enable time bound reviews of applications, deletion of therapeutic inefficiency as a criterion for compensation for research injury, restricting compensation in situations that may actually provide undue inducement to participate in clinical trials (terminal illness, totally unrelated causes of injury, etc.), streamlining the process of approving academic trials and setting up a central fund for compensation in such trials and laying down a mechanism for assessing causality of any injury. It also suggested that the cost of medical care of adverse events should be borne by investigator/sponsor regardless of causality 
and trial arm (standard or experimental) to which the patient was assigned. This seems a somewhat restrictive recommendation, especially in situations in which, for example, two standard treatments are being compared to each other. Of note, this is often the case in "academic" investigator initiated trials that aim to ascertain the most cost-effective treatment option from among many available, but typically operate on shoestring budgets. The counter-argument is the fact that the overwhelming majority of trial participants in India do not have access to health insurance and it is important to build safeguards to protect their health. Among other welcome suggestions of the Committee was not limiting the number of trials per investigator to any specific figure, leaving it to the judgment of the respective Ethics Committees. Unfortunately, this recommendation was overturned by CDSCO which has limited the number of trials per investigator to no more than three at a time. ${ }^{[12]}$ Apart from the fact that it does not take into account varying proficiencies of different investigators and long duration of many longitudinal trials, this order is also likely to severely constrain the conduct of new trials because of relatively low numbers of high quality investigators in each field. Again, as in many other instances, CDSCO has not thought it fit to either discuss this prescription with relevant stakeholders or explain its rationale and benefit.

Among the more contentious recommendations of Ranjit Roy Chaudhury Committee was mandatory audiovisual recording of the informed consent process, which has been accepted and implemented. While the underlying motivation for this regulation is understandable, its mandatory widespread implementation is impractical for several reasons. There are valid concerns about maintaining the privacy of subjects whose audiovisual recording is archived as part of a clinical trial process. Many patients, who are otherwise willing to participate in a clinical trial, may be unwilling for such a recording. Moreover, there are several logistic constraints to consider. These include space, equipment, staff, computing capacity, maintaining duplicate copies and long term archival. Informed consenting often happens in settings such as clinical offices, intensive care units, operation theatres, radiology suites, intervention suites (e.g., cardiac) and community (in case of field research such as screening, vaccines etc.). To ensure audiovisual recording in many of these settings will pose substantial challenges. Some kinds of research (such as community based trials) involve sample sizes in excess of tens of thousands of subjects in a single trial. It will be very difficult, if not impossible, to implement mandatory audiovisual recording and archival of such a large number of consents. A good example is the Tata Memorial Centre trial of acetic acid based cervical cancer screening in an underprivileged community in Mumbai that was recently reported to have resulted in a substantial reduction in mortality. ${ }^{[13]}$ Audiovisual recording of 150,000 consents (sample size of this trial) would have made it a very difficult study to implement.

Central Drugs Standard Control Organization must be complemented for bringing some clarity to the amount of compensation for trial related injury, both in cases of death and other than death. ${ }^{[1,15]}$ Although everyone is not in agreement with the exact formula or quantum of compensation there is at least some certainty about the process. Moreover, in a welcome move, trials involving medical devices, that have hitherto been largely unregulated, have been brought under some systematic oversight. ${ }^{[16]}$

It is evident that clinical trial scenario in India is in a phase of rapid evolution, with new rules being notified at frequent intervals. Their cumulative impact, with some caveats, has been to stifle this vital component of healthcare enterprise, including both investigator initiated and industry sponsored research. Flagrant violations of established ethical principles by many stakeholders in the past has undoubtedly contributed to current predicament. However, regulators and policy planners, incited by well-meaning but overzealous activists and media and an overbearing judiciary, must equally share responsibility for pushing through hastily drafted, ill-considered regulations without adequate participatory process. It must be acknowledged by everyone that, in the modern era of evidence based healthcare, clinical trials are sine qua non if India is to truly to deliver on its promise of adequate quality of life for its citizens. The answers to our healthcare problems are unlikely to be found in clinical trials conducted elsewhere in the world. If we stifle our ability to undertake this vital evidence generating activity, if investigators and patients lose their enthusiasm in being active participants due to onerous regulations, we would have done ourselves incalculable harm. We hope that all stakeholders will be invited to actively participate in creating an enabling regulatory framework, drawing upon best practices from across the world, that will allow clinical trials to flourish in this country.

Bhawna Sirohi, Sudeep Guptal, Digumarti Raghunadharao', Shailesh V. Shrikhande

New India Cancer Charity Initiative, ${ }^{1}$ Advanced Centre for Treatment, Research and Education in Cancer and Department of Medical Oncology, Tata Memorial Centre, Mumbai, ${ }^{2}$ Homi Bhabha Cancer Hospital and Research Centre, Visakhapatnam, Andhra Pradesh, ${ }^{3}$ Department of GI and HPB Surgery, Tata Memorial Centre, Mumbai, Maharashtra, India E-mail: bhawna.sirohi13@gmail.com 
Sirohi, et al.: Clinical trials in India

\section{REFERENCES}

1. Available from: http://www.cdsco.nic.in/writereaddata/ GSR\%2053(E)\%20dated\%2030.01.2013.pdf. [Last accessed on 2014 Aug 01].

2. Divatia JV, Desai A, Pramesh CS, Mohandas KM, Gupta S, Badwe RA. Compensation guidelines for research related injury in India. J Assoc Physicians India 2012;60:53-5.

3. Sugarman J, Bhan A, Bollinger R, Gupta A. India's new policy to protect research participants. BMJ 2013;347:f4841.

4. Karthikeyan G. Investigator-initiated research in India: Nipped in the bud? Natl Med J India 2012;25:313.

5. Available from: http://www.cdsco.nic.in/writereaddata/Report_ of Dr Ranjit Roy.pdf. [Last accessed on 2014 Aug 01].

6. Available from: http://www.cdsco.nic.in/forms/list. aspx ?lid $=1843 \& \mathrm{ld}=31$ [Last accessed on 2014 Aug 01] .

7. Available from: http://www.cdsco.nic.in/writereaddata/ Office \% 200 rder \% 20 dated \% 2019.11.2013.pdf. [Last accessed on 2014 Aug 01].

8. Nundy S, Gulhati CM. A new colonialism? - Conducting clinical trials in India. N Engl J Med 2005;352:1633-6.

9. Pandiya A. Quality of independent review board/ethics committee oversight in clinical trials in India. Perspect Clin Res $2011 ; 2: 45-7$
10. Clinical trials in India: Ethical concerns. Bull World Health Organ 2008;86:581-2.

11. Saini KS, Agarwal G, Jagannathan R, Metzger-Filho $O$, Saini ML, Mistry K, et al. Challenges in launching multinational oncology clinical trials in India. South Asian J Cancer 2013;2:44-9.

12. Available from: http://www.cdsco.nic.in/writereaddata/ officer\%20order\%202.pdf. [Last accessed on 2014 Aug 01].

13. Shastri SS, Mittra I, Mishra GA, Gupta S, Dikshit R, Singh S, et al. Effect of VIA screening by primary health workers: Randomized controlled study in Mumbai, India. J Natl Cancer Inst 2014;106:dju009.

14. Available from: http://www.cdsco.nic.in/writereaddata/ formula2013SAE.pdf. [Last accessed on 2014 Aug 01].

15. Available from: http://www.cdsco.nic.in/writereaddata/ uploaded_for_website_1_FINAL2014.pdf. [Last accessed on 2014 Aug 01].

16. Available from: http://www.cdsco.nic.in/writereaddata/oo3. pdf. [Last accessed on 2014 Aug 01].

How to cite this article: Sirohi B, Gupta S, Raghunadharao D, Shrikhande SV. Clinical trials in India: At uncertain crossroads?. Indian J Med Paediatr Oncol 2014;35:133-5.

Source of Support: Nil. Conflict of Interest: None declared. 